Jurnal Keperawatan Padjadjaran

ISSN 2338-5324 (print)

ISSN 2442-7276 (online)

Online di http://jkp.fkep.unpad.ac.id

DOI : $10.24198 / \mathrm{jkp}$

\title{
Relationship between Workload Performance and Job Satisfaction
}

\author{
Aasma Safdar', F. Sri Susilaningsih ${ }^{2}$, Titis Kurniawan ${ }^{3}$ \\ ${ }^{1}$ New Advance College of Nursing, Lahore, Pakistan \\ ${ }^{2,3}$ Faculty of Nursing Universitas Padjadjaran, Bandung, Indonesia \\ Corresponding Email: asmasahota@gmail.com
}

Submitted: 22-04-2019 Accepted: 02-09-2019 Published: 05-12-2019

\begin{abstract}
In Pakistan's public health care delivery system, charge nurses hold a very challenging position to perform their workload. They have to work very hard to accomplish nursing and non-nursing care tasks which are imposed on them by the system. Overstretching of workload deprives them from concentration which is badly needed for their performance and this creates dissatisfaction which negatively impact on the quality of nursing care. As a result, this study intends to analyses the relationship between workload performance (WLP) and job satisfaction (JS). This correlation study involved 105 charge nurses in Nishtar Medical College and Hospital Multan Pakistan recruited by convenience sampling. Nurses' WLP were collected by using self-developed instrument, and JS were collected by using modified Spector 1985. The collected data were analyze descriptively (mean, SD, frequencies, percentage) and inferentially (Pearson's correlation). The results suggested that nurses' WLP (average time consumption) in the morning (93.83\%) and evening shift (95.63\%) were higher compared with night shift (70.69\%). Additionally, the proportion of time consumed in the morning and evening shift were higher on nursing care activities (Morning = $57.10 \%$, Evening $=52.1 \%$ ) rather than non-nursing care activities. Oppositely, in the night shifts nurses consumed more than half of their time in non-nursing care activities $(55.66 \%)$. Charge nurses observed on moderate level of job satisfaction (mean $=38.6, \mathrm{SD}=5.42$ ). There was no statistically significant correlation between nurses' job satisfaction and workload performance $(\mathrm{p}=.137)$. The findings conclude nurses' high workload and moderate level of job satisfaction and no statistically significant correlation between both. The results suggested that, it is important for hospital management to adopt some better strategies in order to improve WLP and JS.
\end{abstract}

Keywords: Job satisfaction, nursing \& non-nursing care activities, workload performance. 
Aasma Safdar: Relationship between Workload Performance and Job Satisfaction

\section{Introduction}

Nurses are the key care providers in hospitals, they can significantly influence the quality of care provision and patient outcomes. Consequently, hospitals' chase of highquality patient care is based on their ability to engage in some activities that will ensure use of nursing resources effectively (Stokowski, 2009).

According to Lunden (2014), the role of nurses in transforming healthcare is vital in promoting and restoring patients' health through completing the nursing process. This is achieved with nurse collaboration with physicians and multidisciplinary team members to providing physical and psychological support to patients and their families, therefore ensuring job satisfaction, which is a major element for measurement of nurses' workload performance. Draper, Felland, Liebhaber, and Melichar (2008) say "Nurses care for patients in a multitude of ways, and can move into leadership roles in clinics and hospitals with responsibility for overseeing other health care team members. Where they provide hands-on care to patients by administering $\mathrm{medications,}$ managing intravenous lines, observing and monitoring patients' conditions, maintaining records and communicating with doctors".

Snyder, Medina, Bell, and Wavra (2004), asserted that Nurses have to determine the scope of nursing practice, with the responsibility and accountability of provision of nursing services and provide basic patient care that includes but is not limited to taking vital signs, dressing changes, performing phlebotomy, and assisting with activities of daily living. In Pakistan Charge Nurses (CNs) are overburdened with workloads, spending more time in managing the inventories of stock registers, such as general over, linen over, medicine over, etc. besides providing nursing care to patients nurses are occupied with multiple non-nursing tasks, where they have to manage and account for item ranges from needle to oxygen cylinder; from bed sheet to the bed fixing; from receiving the medicines to the distribution and maintaining all kind of stock registers with the constant updating records. Chauhan (2014), stated that medical sector in Pakistan has historically been more preoccupied with cure rather than care, the existing nurse- patient ratio in Pakistan is approximately 1:50 whereas the ratio prescribed by the Pakistan Nursing Council (PNC) is 1:10 in general areas and 2:1 in specialized areas.

Hamid, Malik and Ramzan, (2013) reported that most dissatisfying factors at work and within the work setting are high workload.

There is paucity of literature in Pakistan on workload performance \& job satisfaction, this study is important as it was the first attempt to study the measurement of nursing workload performance for nursing and nonnursing care activities.

This relationship is reciprocal, meaning people who are satisfied with life tends to be satisfied with their job and people who are satisfied with their job tends to be satisfied with life. Therefor it's important to further study the overload work performance in the context of nursing and non- nursing care activities of nurses and its relation with their job satisfaction. As a result, there would a drive in the authorities' to bring some change in policy in order to divide the task by various personals. This will be helpful to raise the quality of health care delivery system

\section{Method}

A descriptive cross sectional study with method of primary data collection was adopted to extract information from all charge nurses working at Nishtar Medical College \& hospital Multan, Pakistan. Sample size collection prevalence (p) was assumed 50\% with confident interval of $95 \%(z=1.96)$ and $\mathrm{Q}$ was 1-p, margin of error is assumed to be $10 \%$ on the basis of this my sample size is 96 additional $10 \%$ is added for refusals the total sample size is 105 recruited by convenience sampling. The questionnaire validity was checked on same group of charge nurses by the consultations of professionals in the field. Reliability study was conducted using Cronbach's alpha. Nurses' Workload performances were collected by using selfdeveloped instrument, and Job Satisfaction were collected by using modified Spector 1985. The collected data were analyze 
Aasma Safdar: Relationship between Workload Performance and Job Satisfaction

descriptively (mean, SD, frequencies, correlation).

percentage) and inferentially (Pearson's Results

Table 1 Characteristics of The Respondents $(n=105)$

\begin{tabular}{|c|c|c|}
\hline Characteristics & Frequencies & Percentage \\
\hline \multicolumn{3}{|l|}{ Marital status } \\
\hline Married & 53 & 50.5 \\
\hline Unmarried & 49 & 46.7 \\
\hline Divorce & 3 & 2.9 \\
\hline \multicolumn{3}{|l|}{ Professional qualification } \\
\hline Charge Nurses (CNs) & 62 & 59 \\
\hline CNs with (DWA) & 4 & 3.8 \\
\hline CNs (DTA) & 2 & 1.9 \\
\hline CNs with BSc Nursing & 31 & 29.5 \\
\hline $\begin{array}{l}\text { CNs with other then nursing } \\
\text { qualification }\end{array}$ & 6 & 5.7 \\
\hline \multicolumn{3}{|l|}{ Job experience } \\
\hline$<1-5$ years & 55 & 52.4 \\
\hline $6-10$ years & 34 & 32.4 \\
\hline $11-15$ years & 11 & 10.5 \\
\hline $16>20$ years & 5 & 4.8 \\
\hline \multicolumn{3}{|l|}{ Present placement } \\
\hline Medical unit & 11 & 10.5 \\
\hline Surgical unit & 22 & 21 \\
\hline Pediatric unit & 15 & 14.3 \\
\hline Obstetrics & 11 & 10.5 \\
\hline Emergency unit & 7 & 6.7 \\
\hline Cardiac unit & 10 & 9.5 \\
\hline Other & 29 & 27.6 \\
\hline \multicolumn{3}{|l|}{ Present shift } \\
\hline Morning & 49 & 46.7 \\
\hline Evening & 29 & 27.6 \\
\hline Night & 27 & 25.7 \\
\hline \multicolumn{3}{|l|}{ Age (Years) } \\
\hline Mean & (29.47) SD (5.50) & \\
\hline Minimum - Maximum & $25-45$ & \\
\hline
\end{tabular}

Table 2 Total average time of WLP/per unit (Nursing and Non-nursing care activities)

\begin{tabular}{cccccc}
\hline Shifts & $\begin{array}{c}\text { Average Total } \\
\text { amount of time }\end{array}$ & Percentage & $\begin{array}{c}\text { Total actual } \\
\text { time* persons } \\
\text { on duty in a } \\
\text { unit }\end{array}$ & $\begin{array}{c}\text { Total Nursing } \\
\text { care activities } \\
\text { average } \\
\text { minutes and } \\
\text { percentage }\end{array}$ & $\begin{array}{c}\text { Total Non- } \\
\text { nursing care } \\
\text { activities } \\
\text { average } \\
\text { minutes and } \\
\text { percentage }\end{array}$ \\
\hline Morning $(\mathrm{n}=49)$ & 309,22 & 93.83 & $360 * 3=1080$ & $205.57(57.10 \%)$ & $132.24(36.73 \%)$ \\
\hline
\end{tabular}


Aasma Safdar: Relationship between Workload Performance and Job Satisfaction

\begin{tabular}{lllllc}
\hline Evening $(\mathrm{n}=29)$ & 344.29 & 95.63 & $360 * 3=1080$ & $187.51(52.1 \%)$ & $156.78(43.56 \%)$ \\
Night $(\mathrm{n}=27)$ & 508.98 & 70.69 & $720 * 2=1440$ & $305.46(42.43 \%)$ & $\begin{array}{c}203.51(55 . \\
66 \%)\end{array}$ \\
\hline
\end{tabular}

Table 3 Frequency and Percentage of WLP

\begin{tabular}{lccc}
\hline \multicolumn{1}{c}{ Shifts } & $\begin{array}{c}\text { Low than average } \\
\text { Frequency } \\
\text { (percentage) }\end{array}$ & Average Percentage & $\begin{array}{c}\text { Higher than average } \\
\text { Frequency } \\
\text { (percentage) }\end{array}$ \\
\hline Morning $(\mathrm{n}=49)$ & $23(46.9)$ & 93.83 & $26(53.1)$ \\
Evening $(\mathrm{n}=29)$ & $14(48.2)$ & 95.6 & $15(51.7)$ \\
Night $(\mathrm{n}=27)$ & $16(59.2)$ & 70.6 & $11(40.7)$ \\
\hline
\end{tabular}

Table 4 Level of Job Satisfaction

\begin{tabular}{lccc}
\hline \multicolumn{1}{c}{ Shifts } & $\begin{array}{c}\text { Lower than average } \\
\text { Frequency } \\
\text { (percentage) }\end{array}$ & Average & $\begin{array}{c}\text { Higher than average } \\
\text { Frequency (percentage) }\end{array}$ \\
\hline Morning $(\mathrm{n}=49)$ & $24(48.9)$ & 38.32 & $25(51.0)$ \\
Evening $(\mathrm{n}=29)$ & $12(41.3)$ & 38.14 & $17(58.6)$ \\
Night $(\mathrm{n}=27)$ & $14(51.1)$ & 39.89 & $13(48 . \mathrm{I})$ \\
\hline
\end{tabular}

Table 5 Correlation Between The WLP and JS as per shift

\begin{tabular}{lcccc}
\hline Shifts & $\begin{array}{c}\text { WLP Total average } \\
\text { minutes }\end{array}$ & $\begin{array}{c}\text { JS Total average } \\
\text { score }\end{array}$ & r & p value \\
\hline Morning & 309.22 & 38.32 & -.058 & 0.69 \\
Evening & 344.29 & 38.13 & 0.21 & 0.26 \\
Night & 508.98 & 39.88 & 0.086 & 0.67 \\
\hline
\end{tabular}

Table 6 Correlation Between The WLP and JS (n=105)

\begin{tabular}{cccc}
\hline $\begin{array}{c}\text { WLP Total averages } \\
\text { minutes }\end{array}$ & JS Total average score & r & P value \\
\hline 383.64 & 38.68 & 0.146 & 0.137 \\
\hline
\end{tabular}

\section{Characteristics of Respondents}

The study also considered some other vital information in the demography which includes designation, job experience, professional qualifications, present placement and present shift.

Table 1 shows that half of the respondents were married (50.5), more than half were charge nurses $(59 \%)$ with nonspecific qualification, while half of the respondent's Job experience $(50.4 \%)$ were $<1-5$ years, where $(27.6 \%)$ respondents were placed in other departments of the hospital, almost half $(46.7 \%)$ were on morning shift duty, and minimum age respondents recorded 25, maximum age were 45 with the 29.45 mean and 5.50 SD.

\section{Nursing Workload Performance}

Table 2 describes that the average time and percentage, charge nurses spend to achieve their workload performance in their three shifts and average time is divided with the no of persons who were present on shift in per unit because the nursing and non-nursing tasks(workload) were assigned to all nurses 
Aasma Safdar: Relationship between Workload Performance and Job Satisfaction

who were deployed in unit, further to get actual workload the work also distributed on persons who were present on shift in a unit, so the actual minutes 360 minutes of morning, evening and 720-night shift multiplied with the no of charge nurses present in one unit in each shift to achieve the real minutes of WLP.

Table 2 represented that the respondents in morning shift $(93.83 \%)$ and evening shift $(95.63 \%)$ consumed almost full of time to accomplish their workload performance, as compare to night shifts where workload is low $(70.69 \%)$. To perform nursing care activities respondents reported more the half of time consumed (57.10\%) in morning shift, $(52.1 \%)$ in evening shift while less than half time consumed $(42.43 \%)$ in night shift, to perform non-nursing care activities the scenario is opposite, respondents consumed less time in morning and night shift and more in night shift.

Table 3 indicates that respondents from morning $(53.1 \%)$ and evening $(51.7 \%)$ shifts reported that consumed more than half of, above then average time consumed in WLP, where respondents from night shift resulted more than half of time lower than average $(59.2 \%)$ consumed to accomplish WLP.

\section{Job Satisfaction}

Table 4 indicates that the average moderate level of job satisfaction of respondents in all three shifts from the total score of 75 .

Table 6 shows that correlation between morning shift WLP and JS ( $\mathrm{r}=-.058)$, while their correlation between evening shift WLP and JS $(r=.21)$.

Table 6 indicates that, there is no statistically significant correlation between WLP \& JS with the $.137 \mathrm{p}$ value.

\section{Discussion}

The purpose of this study was to examine the relationship between job satisfaction and workload performance (nursing care activities and non-nursing care activities) of charge nurses of Nishtar Medical College \& Hospital Multan. This chapter discusses the findings of the research questions surrounding characteristics of the respondents, workload performance for nursing care activities and non-nursing care activities, and job satisfaction, in addition, relationships between these variables are compared and contrasted with other research findings on the same topics.

The study aimed to figure out the workload performance which resulted that charge nurses consumed full of their time more than $90 \%$ to accomplish their tasks in morning and evening shift as contrast with night shift average time consumed $(70.69 \%)$ which means workload is high in morning and evening this results contrasted with Debergh et al. (2012) study of measurement of workload per shift in the ICU where researcher measured nursing care activities per shift was $(85.5 \%)$. In general nursing workload recorded high in ICU as compare to other departments, whereas this study recorded higher workload then ICU from all department of the hospital.

The study findings observed the proportion of time consumed on nursing and non-nursing patient care activities, charge nurses consumed more than half of their time (Morning $=57.10 \%$, Evening $=52.1 \%$ ) to perform nursing care patient activities whereas less than half time (Morning = $36.73 \%$, Evening $=43.56 \%$ ) to perform nonnursing care activities, actually nurses in Nishtar Medical college and hospital have higher non-nursing activities workload but sometimes they took medicine expense register to their home to complete their tasks and most of the time they keep forward to night shift as evident in table 4.2 non-nursing activities recorded $(55.66 \%)$ average time in night shift.

In addition, findings of the study recorded that charge nurses spend lowest minimum average time on 7.429 minutes for making nursing care plan and highest maximum average time 82.86 minutes for medicating the patients for nursing care activities, which means charge nurses don't have enough time to make appropriate nursing care plans, conceptually \& factually it's not possible to make nursing care plans of one unit patients which are 40 to 80 in number within 7.429 minutes.

For non-nursing care activities this study recorded charge nurses spend minimum average time in writing of demands of supplies and maximum average time (102.33 
Aasma Safdar: Relationship between Workload Performance and Job Satisfaction

minutes ) on managing medicine expense, similarly Jackson Healthcare (2012) reported that about $78 \%$ of nurses testified spending at least two hours (120 minutes) per shift on non-nursing care activities (Documenting information in multiple locations, Completing logs, checklists, and collecting data, Traveling to equipment, supply, and utility rooms, and Entering and reviewing orders ). Whereas this study recorded charge nurse's maximum average time (203.51 minutes) which means three and half hours (Reference table is available in appendix).This study intended to weigh the level of job satisfaction of charge nurses of Nishtar Medical College and Hospital Multan which concluded total job satisfaction mean 38.86 in all three shifts, which indicates nurses on a moderate level of job satisfaction despite of any shift, findings of this study are contradicted to Jaiswal et al. (2015) which reported job satisfaction rate highest (68\%) among nurses.

Job satisfaction seems like a complex phenomenon as this study evident that the 15 item of job satisfaction (scored 1 low to 5 high) the 4 items of JS, equitable benefits, rewards, job is enjoyable \& adequate opportunity to utilize and update skills and talent, was scored between $>3 \&>4$ which suggest the high level of satisfaction with these items, while 8 items of JS, salary ,communication within the organization, organizational supervision system, appreciation of work, co-workers, sense of pride, and bickering/ fighting at work were scored $>2 \&<3$ which suggested the moderate level of job satisfaction of these items, and 3 items of JS heavy paperwork, high workload, and chance of promotion were scored very low $>1 \&<2$ which suggested charge nurse are not happy at all with high workload, high paperwork and chances of promotion therefor these items scored very low. Perhaps one of the interesting results of this study shows that the age, marital status, job experience, and present placement of the respondents were not influence the workload performance and job satisfaction of charge nurses. Hence the present shift of the respondents recorded the different level of workload of nursing and non-nursing care activities.

The exciting finding on professional qualification have the effect on job satisfaction as this study evident that the charge nurses with higher nursing education also such as BSc Nursing table 4.1 (29.5\%) were also deputed as charge nurses which supposed to be on higher rank according to their qualification, therefore the job satisfaction ( item no 2: there is really little chance of promotion on my job) scored very low 1.2 out of 5 which indicates charge nurses are not satisfied with their chance of promotion.

In general this study aimed to figure out the relationship between workload performance and job satisfaction which statistically proved that there is no significance correlation between workload performance and job satisfaction despite of all three shifts with the $p$ value (.137) among the charge nurses, the study didn't proved the significant correlation as researcher did not control the other factors that also contribute job satisfaction as literature proved that there are several factors control job.

\section{Strength and Limitation of The Study}

The strength of the study was the questionnaire that used in this study was validated by three experts, and statistically had acceptable reliability score.

Satisfaction of nurses working in tertiary level Health care settings in Pakistan Bahalkani, Kumar, Lakho, Mahar, Mazhar, and Majeed (2011) found 86\% respondents were dissatisfied their job due to the poor work environments, poor fringe benefits, dignity, responsibility given at workplace and time pressure, and Poor lack of training opportunities, proper supervision and Sultana, Riaz, Mahmood, and Khursih, (2011) also observed 37.14\% nurses least satisfied with their job in the context of working environment, dealing of health care professionals with nurses, and attitude of the patients and their attendants towards nurses. Further, the set of data were used in this study were homogeneous in nature therefore it was difficult to find the strong significant correlation.

The financial resources were limited due to that the generalization of the findings remain limited and different findings possibly were found in other settings, particularly the setting with varies health care delivery model. 
Aasma Safdar: Relationship between Workload Performance and Job Satisfaction

\section{Conclusion}

Firstly, this study assess the proportion of time consumed on nursing and non-nursing patient care activities the findings concluded that charge nurses in morning and evening shift consumed more than half of their time to perform nursing care activities and less than half time to perform non-nursing care activities, which is opposite to night shifts where nurses consumed more than half of their time in non- nursing care activities.

Secondly this study intends to weigh the level of job satisfaction of charge nurse and findings concluded that charge nurses are on moderate level of job satisfaction.

Thirdly the study results observed that there is no significance correlation between workload performance and job satisfaction among charge nurses of Nishtar Medical College and Hospital.

It is clearly evident from this study that charge nurses consumed their full time on workload performance and $>40 \%$ average time on conducting non-nursing care activities, which are related to record keeping of expenses of various supplies manually, therefor its strongly recommended the adaptation of Electronic Health records \& Management information system it could be brought to further minimize the level of workload and nurses could be able to provide quality nursing care with the higher level of job satisfaction. Further it's suggested to hospital management to adopt some better strategies to overcome nurse's workload and improve nurse's job satisfaction level moderate to highest.

The study provided a research base evidence for nurses and other professional healthcare provider, university member, and researcher for further research and knowledge development.

In Future empirical work needs to test and examine how addressing with different contributing factors might foster nurses' job satisfaction with their workload performance within the hospital and also researcher recommends that this study should be replicated in vary/multi setting with the bigger number of sample measurements in Pakistan in order to further clarify and strengthen the evidences to maximize the benefits for nursing care services in order to provision of quality care.

\section{References}

Bahalkani, H,A., Kumar, R., Lakho, A.R., Mahar, B., Mazhar S.B., \& Majeed, A. (2011) Job satisfaction in nurses working in tertiary level health care settings of Islamabad Pakistan. Journal Ayub Med College Abbottabad, 23(3).

Chauhan, N. (2014). Nursing in Pakistan: Handle with care [web log post]. Retrieved from http://tribune.com.pk/story/801156/ nursing-in-pakistan-handle-with-care.

Debergh at al,. (2012). measuring the nursing workload per shift in the ICU: journal of Intensive care medicine 38(9): 1438-44

Debergh, et al. (2012). Measuring the nursing workload per shift in the ICU. Journal of Intensive Care Medicine 38(9), 1438-44.

Draper, D., Felland, L., Liebhaber, A., \& Melichar, L. (2008). The role of nurses in hospital quality improvement. Care Management, 14(5), 6-287p.

Hamid, S., Malik, A,U., Kamran, I., \& Ramzan, M. (2013). Job satisfaction among nurses working in the private and public sectors: A qualitative study in tertiary care hospitals in Pakistan. Online journal of NCBI, 7: 25-35. doi: 10.2147/JMDH.S55077.

Jackson Healthcare. (2012). Survey: Nurses spend $25 \%$ of shift on indirect patient care. Retrieved from https://www.advisory.com/ daily briefing/2012/02/02/nurses.

Jaiswal, M., Dudhe, R., \& Sharma, P. K. (2015). Nanoemulsion: an advanced mode of drug delivery system. 3 Biotech, 5(2), 123127. 
Aasma Safdar: Relationship between Workload Performance and Job Satisfaction

Pakistan Nursing Council. (1973). Pakistan Nursing Council. Retrieved August 12th 2016 from http://pnc.org.pk/PNC_Registration. htm.

Snyder, D., Medina, J., Bell, L., \& Wavra, A. (2004). American association of critical care delegation handbook (2nd Ed.).

Spector, P.E. (1985). Measurement of human service staff satisfaction: Development of the Job Satisfaction Survey. American Journal of
Community Psychology, 13, 693-713.

Stokowski, L.A. (2009). Nurse staffing for safety. Journal of Medscape.

Sultana, A., Riaz, R., Mehmood, F., \& Khurshid, R. (2011). Level of job satisfaction among nurses working in tertiary care hospitals of Rawalpindi. Rawal Medical Journal, 36(2), 150-154. 